\title{
JOHN ZEISEL NA FAUUSP
}

\author{
Sheila Walbe Ornstein
}

(1) Zeisel, John. Inquiry by design. Environment/ Behavior/Neuroscience in architecture, interiors, landscape and planning. Nova York: W. W. Norton \& Company, 2006. 400p. (edição revisada e edição data de 1984; em 1994 foi traduzido para 0 japonês e em 1996 para o mandarim. Transformou-se em clássico e livro-texto para os pesquisadores, nas áreas de ambiente e comportamento e de Avaliação Pós-Ocupação (APO) pela forma didática com que apresenta métodos e técnicas aplicáveis nesse campo, destacando sempre a importância de indagar correta e cientificamente o usuário de ambientes, para atender às suas necessidades ambientais, se o propósito é a realização de projetos arquitetônicos ou urbanos de qualidade.
John Zeisel, autor do clássico Inquiry by design ${ }^{1}$, presenteou um público perto de 80 pessoas, entre docentes, projetistas, pós-graduandos e graduandos, sobretudo de arquitetura e urbanismo, com uma cativante conferência, seguida de debates, sob o tema Environment and behavior methods: the role of neuroscience in design.

O evento, ocorrido dentro do Programa de Pós-Graduação em Arquitetura e Urbanismo da FAUUSP, em 27 de abril de 2007, fez parte das atividades da AUT 5805 - Avaliação Pós-Ocupação (APO) do ambiente construído, mas seu interesse, certamente, extrapolou em muito o âmbito da disciplina em questão. Zeisel nos brindou com essa atividade acadêmica, em uma única semana de permanência em São Paulo, como consultor para um empreendimento voltado à área de saúde e habitação.

Zeisel, sociólogo com doutorado pela Columbia University, lecionou por muitos anos na Harvard's Graduate School of Design, no Planning Department of Yale University e no Sociology and Architecture Department of McGil University, EUA. Desde 1993 é co-fundador da Hearthstone Alzheimer's Family Foundation e da Hearthstone Alzheimer Care Ltd.

Conta, em seu currículo, com um vasto conjunto de pesquisas e de consultorias voltadas ao desenvolvimento criterioso de programas de necessidades, de aplicações de APOs e de estudos das Relações Ambiente Construído versus Comportamento Humano (RACs), voltados sempre às populações específicas, como os idosos, os portadores de dificuldade de locomoção ou fornecimento de suporte a projetos e/ou adaptações de edifícios destinados a essas populações, tais como hospitais, residências e condomínios residenciais. Nos últimos anos, tem se dedicado à caracterização e ao desempenho de ambientes para pessoas com Alzheimer.

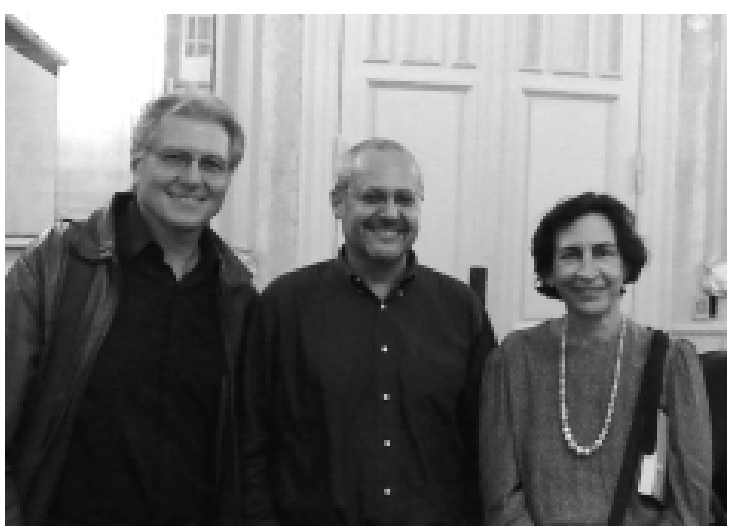

Bruno Padovano, John Zeisel e Sheila Walbe Ornstein Crédito: Helena Quintana Minchin 
(2) O pesquisador identifica, no cérebro, os paradigmas do processo de desenvolvimento, das RACs e da neurociência (neurônios e sua relação com a memória ou a perda desta), dividindo nos setores "intérprete", "ator", "o que estabelece comparações" e, finalmente, "aquele que busca coerência”.
Zeisel, assim como Sommer, Sanoff, Bechtel e Preiser, pertencem ao conjunto de pioneiros nos estudos das RACs, os quais souberam transformar, com didatismo e mestria, respostas de usuários do ambiente construído em insumos para projetos.

O impacto do ambiente - ou da qualidade arquitetônica ou, ainda, da ausência desta - nas atividades cotidianas das pessoas, foi o assunto do qual sua conferência tratou. Abordando as situações mais críticas - pacientes com Alzheimer - para os quais a perda da memória e, portanto, das lembranças do passado mais remoto ao mais recente ocorre -, Zeisel enfatiza, com grande conhecimento de causa, que a boa arquitetura pode colaborar de modo decisivo para atenuar as barreiras do dia a dia nesses casos, com percursos e detalhes internos e externos a apontarem claramente os caminhos a serem perseguidos e também com ambientes e objetos (inclusive de artes) estimulantes. Por outro lado, Zeisel evidencia que as demandas por uma boa arquitetura e com os atributos ora especificados, não podem ser entendidas como prerrogativas exclusivas desses usuários especiais, e sim da boa arquitetura - indutora do bem-estar e da qualidade de vida - em geral, à qual todos os usuários, sem distinção, têm direito.

Zeisel prendeu a atenção da audiência, tendo em mãos um modelo de plástico colorido do cérebro humano para elucidar como este comanda comportamentos e atividades ${ }^{2}$, os quais podem ocorrer de modo mais ou menos prazeroso, mais ou menos produtivo, e com mais ou menos bem-estar, dependendo do ambiente. Ou seja, Zeisel pondera que, se os arquitetos conhecessem melhor os conteúdos da neurociência, poderiam projetar melhor no que diz respeito ao seu público-alvo. Nessa linha, aponta que o tratamento exclusivamente medicamentoso para Alzheimer pode ser minimizado, se o ambiente for corretamente projetado e prover as informações, direcionamentos e os estímulos adequados.

A conferência lançou pistas contundentes sobre o potencial de aproximação entre os estudos das RACs e o projeto de arquitetura, reiterando o contexto interdisciplinar em que se inserem as pesquisas e os projetos em arquitetura e urbanismo, agora com a inclusão dos trabalhos no campo da neurociência.

Para quem não foi viável estar presente na conferência, vale a pena a leitura do Inquiry by design (ver nota 1), entre outras obras do mesmo autor, na medida em que aborda em profundidade os temas tratados na Vila Penteado, contemplando vários exemplos e estudos de caso.

\section{Nota}

A realização da conferência contou com o apoio do Hiléa (Vivência e desenvolvimento para idosos).

Site: www.hilea.com.br

\section{Sheila Walbe Ornstein}

Professora titular da Faculdade de Arquitetura e Urbanismo da Universidade de São Paulo e pesquisadora-bolsista do Conselho Nacional de Desenvolvimento Científico e Tecnológico.

e-mail: sheilawo@usp.br 